\title{
Estudio sobre los factores de riesgo de caries y evaluación de un test indicador del pH y revelado de la placa y la capacidad tampón de la saliva
}

\author{
R. Blasco Sansano ${ }^{a}$, MD. Castellar Ponce ${ }^{b}$, N. Llorca Salort ${ }^{c}$, \\ J. Valero Rosique ${ }^{d}$, S. García Espinosa \\ ${ }^{a}$ Médico Estomatólogo. Unidad de Odontología Preventiva Raval-Pla.

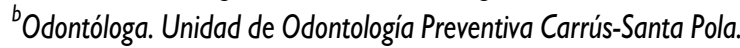 \\ 'Odontóloga. Unidad de Odontología Preventiva Sapena-Crevillente. \\ ${ }^{d}$ Médico, Odontólogo. Unidad de Odontología Preventiva Altabix-Toscar. \\ ¿Odontóloga.
}

Departamento 20. Agència Valenciana de Salut (AVS). Alicante.

Rev Pediatr Aten Primaria. 2009; I 1:33-47

Ramón Blasco Sansano, pamalira@medtelecom.net

Resumen

Objetivos: cuantificar los factores de riesgo de caries y determinar la asociación entre los valores del pH de la placa, la capacidad tampón de la saliva y el revelado de la placa con los indices de caries.

Material y métodos: estudio descriptivo transversal. Selección: muestreo consecutivo. Población: 339 niños de 6 años y 258 de 12, (319 varones y 278 hembras). Encuesta a los padres, exploración bucal y realización de tres pruebas incruentas sobre el niño. Variables: nacionalidad, índices de caries, cepillado dental, consumo de azúcares, empleo de colutorios fluorados, pH de la placa, capacidad tampón de la saliva, indice de placa coloreada, lesiones en dientes y superficies resistentes, caries activas, empastes en mal estado y presencia de aparatología ortodóncica.

Resultados: un 5,2\% (31/597) son inmigrantes. Índice co(d) (media del número de piezas dentarias temporales careadas y empastadas) 6 años: 1,5. Índice $C A O(D)$ (media del número de piezas dentarias definitivas con caries, extraídas por caries y empastadas) 12 años: 1,08. Un 89,3\% (533/597) se cepilla al menos una vez al día; sólo el 4,5\% lo hace correctamente. Consumo ocasional de azúcares entre comidas: $36,7 \%$ (219/597). El pH de la placa es alcalino en un 42,4\% (253/597). La saliva tiene una capacidad tampón normal en el 22,3\% (133/597). Hay 156 (26,1\%) con caries activas. Encontramos asociación significativa estadísticamente ( $p$ $<0,05)$ entre el $\mathrm{pH}$ de la placa ácido y valores más altos de caries.

Conclusiones: es más fácil cepillarse que mantener hábitos dietéticos saludables. La calidad del cepillado es muy baja. Tan solo la prueba del pH de la placa tiene utilidad predictiva.

Palabras clave: Caries dental, Odontología preventiva, Placa dental, Saliva.

Los autores declaran no presentar conflictos de intereses en relación con la preparación y publicación de este artículo. 
Abstract

Objectives: quantify the factors of dental caries risk as well as determine the association among dental plaque $\mathrm{pH}$ values, the buffer capacity of the saliva and the revealed of the plaque with the tooth decay indexes.

Material and methods: cross-sectional study. Selection: serial sampling. Population of: 339 sample group of 6 years old children and 258 sample group of 12 years old children (319 male and 278 female, 597 in total). Survey to parents, oral examination and realization of three non-invasive tests on each child. Variables: nationality, dental caries indexes, dental brushing, sugar consumption, use of fluoride mouthwashes, $\mathrm{pH}$ of the plaque, buffer capacity of the saliva, index of coloured plaque, injuries in teeth and resistant surfaces, active decay, fillings in poor condition and orthodontic treatments.

Results: regarding the whole sample of 597 people, 5.2\% (31/597) are immigrants. Index $\operatorname{co}(d)$ at six years: 1.5. CAO (D) at twelve: 1.08. Eighty-nine and three percent (533/597) brush their teeth at least once a day, even though only $4.5 \%$ do it correctly. On the other hand, 36.7\% (219/597) occasionally consume sugars between meals. The pH of the plaque is alkaline in 42.4\% (253/597) and the saliva has a normal buffer capacity in $22.3 \%$ (133/597). There are 156 cases (26.1\%) with active decay. An association statistically significative $(p<0.05)$ has been found between the $\mathrm{pH}$ of the acid plaque and higher values of tooth decay.

Conclusions: we found that it is easier to brush one's teeth than maintaining healthy dietetic habits. When brushing one's teeth the quality of brushing is very poor. Testing the $\mathrm{pH}$ of the plaque is the only fact that is useful as a prediction.

Key words: Dental caries, Preventive dentistry, Dental plaque, Saliva.

\section{Introducción}

Los estudios epidemiológicos realizados a partir de los años 70 indican un descenso de los índices de caries en los niños. Sin embargo, el problema sigue siendo sanitariamente importante, los últimos trabajos demuestran que el decrecimiento se ha estabilizado y no aparece una trayectoria descendente. La desaparición de la enfermedad no se visualiza a corto plazo y la lucha contra la misma sigue siendo válida.

El objetivo general del programa de salud bucodental de la Comunidad Valenciana, que inició sus actividades en
1985, es mejorar la salud oral de los niños/niñas de 0 a 14 años previniendo la aparición de los problemas bucodentales más frecuentes. Dentro de las actividades que realizamos en las unidades de Odontología preventiva (UOP) se considera prioritario el aunar esfuerzos en la atención a los niños con riesgo evidente de caries (asesoramiento dietético e higiénico, sellados, aplicación tópica de flúor a altas concentraciones, aplicación de barnices de clorhexidina, etc.). Por otro lado, dos de las conclusiones del Estudio de salud bucodental infantil en la Comunidad 
Valenciana del año 2004 son: "la prevalencia de caries en dentición permanente y el índice $\mathrm{CAO}(\mathrm{D})$ a la edad de 12 años se mantiene en unos niveles similares a los de 1998" (tabla I) y "se está produciendo un fenómeno de concentración de la mayor parte de las caries en un porcentaje pequeño de la población"1. Se sabe que más del $75 \%$ de la enfermedad incide y se concreta en el $25 \%$ de la población (de riesgo) ${ }^{2}$. La selección de niños por su riesgo de caries se convierte en un objetivo de gran importancia debido a la inclusión de las nuevas prestaciones (obturaciones y tratamientos pulpares en dentición permanente dirigido a niños/as de 7 y 8 años) que se van o ofrecer en el sistema de salud público, tras la entrada en vigor del Real Decreto 111/2008 de 1 de febrero. La limitación de recursos tanto humanos como materiales, nos obliga a los profesionales de la salud bucodental en el marco público a dirigir nuestros esfuerzos a aquellos niños que más lo precisen y dejar a los de riesgo bajo por ejemplo en manos de los enfermeros y pediatras dentro de los controles del programa de supervisión del desarrollo infantil. En cualquier caso, esta medida se valorará localmente según las características de cada zona de salud.

No cabe la menor duda de que la existencia previa de la enfermedad es el mejor predictor del futuro incremento de caries, como así lo indican multitud de trabajos. La existencia de caries en dentición temporal a los 6 años tiene un alto valor predictivo de riesgo de caries en dentición permanente entre los 7 y 13 años. La naturaleza multifactorial y crónica de la enfermedad, junto al hecho de que es un proceso cam-

\begin{tabular}{ll}
\hline Tabla I. Definiciones \\
\hline co(d) & $\begin{array}{l}\text { Es la suma del número de dientes temporales careados (componente c) y los dientes } \\
\text { temporales obturados (componente o). } \\
\text { El índice co(d) sería la media de los co(d) de los niños explorados. }\end{array}$ \\
\hline co(s) & $\begin{array}{l}\text { Es la suma del número de superficies temporales careadas y las superficies temporales } \\
\text { obturadas. } \\
\text { El índice co(s) sería la media de los co(s) de los niños explorados. }\end{array}$ \\
\hline CAO(D) & $\begin{array}{l}\text { Es la suma del número de dientes permanentes careados (componente } \mathrm{C} \text { ), } \\
\text { ausentes por caries (componente } \mathrm{A} \text { ) y obturados (componente O). } \\
\text { El índice CAO(D) sería la media de los CAO(D) de los niños explorados. }\end{array}$ \\
\hline CAO(S) $\quad$ Es lo mismo pero referido a superficies dentales permanentes afectadas.
\end{tabular}


biante, hacen muy difícil esta selección ${ }^{3}$. Un estudio afirma que el nivel educativo de la madre se comporta como un factor predictivo del incremento de caries en la dentición permanente ${ }^{4}$. El recuento de Streptococcus mutans en saliva no tiene valor predictivo de nuevas caries $^{5}$. La presencia de caries en segundos premolares y molares a la edad de 12 años se comporta como el mejor predictor de más lesiones a los 18 años $^{6}$. La variable de predicción que mejor contribuye en el programa informático "Cariogram" es el recuento con Streptococcus mutans, seguido por el índice $C A O(D)$ (tabla I) y la capacidad tampón de la saliva ${ }^{7}$. Se acepta que el valor de las pruebas de susceptibilidad a la caries es mucho mayor en estudios de grupos de población que en el paciente individual, pero su importancia en la práctica clínica se deriva de su valor educativo ${ }^{8}$. Se han elaborado modelos de predicción con distintas variables ante reconocimientos bucales a niños de 1,5 años y luego a los 3, los cuales reconocen que no pueden predecir el riesgo de caries, pero sí los casos en que no se va a desarrollar la enfermedad ${ }^{9}$. La baja concentración de calcio en la placa presenta una modesta capacidad preventiva ${ }^{10}$.

Así pues, debemos seguir experimen- tando con los distintos tests que salen al mercado para conocer el alcance de la utilidad de los mismos y aplicarlos en la medida de lo posible en la detección de la población más expuesta. Estos tests deben ser sencillos, de bajo coste y de rápida ejecución. Los recuentos bacterianos de Lactobacillus y Streptococcus mutans son muy útiles pero el precio, y el periodo de incubación de unos 4 días no los hacen prácticos para su uso de forma generalizada.

Por otro lado, no existe en la actualidad un método definitivo que inhiba la formación de la placa bacteriana. El objetivo que deseamos alcanzar para prevenir la caries es la eliminación de la propia placa ya constituida. Si no hay placa no habrá caries. Siendo realistas, el control absoluto de la misma por parte de la población es casi imposible debido, sobre todo, al mal uso de las técnicas del cepillado dental (ya sea por desconocimiento o falta de habilidad) y la ausencia de la imprescindible motivación para el mantenimiento de la salud bucodental. El test del revelado de la placa es muy útil para que los pacientes conozcan las características y la localización de la misma y ello se traduzca en la mejora del cepillado y de la dieta. La instauración de un hábito mantenido redundará en un beneficio no solo con- 
tra la caries sino también contra la enfermedad periodontal.

Los objetivos específicos son:

- Determinar la prevalencia (\% de niños con caries en dentición decidua y en la dentición definitiva), los índices de caries co(d), co(s), CAO(D) y $\mathrm{CAO}(\mathrm{S})$ (tabla I), y mediante un cuestionario, conocer la frecuencia del cepillado diario, el consumo de azúcares, el empleo de colutorios fluorados o la asistencia previa a una UOP.

- Determinar los valores del pH de la placa, la capacidad tampón de la saliva y el índice de placa coloreada.

- Determinar la incidencia de una serie de factores o signos relacionados con el riesgo de caries: población inmigrante, lesiones en incisivos-caninos y en superficies resistentes, caries activas, empastes en mal estado y presencia de aparatología ortodóncica.

- Determinar la relación entre los valores del pH de la placa y los índices co(s) en el grupo de 6 años y CAO(D) (tabla I) en el de 12 años.

- Determinar la relación entre la capacidad tampón de la saliva y los valores del co(s) y $\mathrm{CAO}(\mathrm{D})$ (tabla I) de los niños de 6 y 12 años respectivamente.
Determinar la relación entre el índice de placa y los índices co(s) en el grupo de 6 años y CAO(D) (tabla I) en el de 12 años.

\section{Material y métodos}

Estudio descriptivo transversal. La población objeto de nuestro estudio es la infantil de 6 y 12 años del Departamento 20 de Salud de la Comunidad Valenciana que engloba los municipios de Elche, Crevillente y Santa Pola. Según los últimos datos obtenidos del SIP (sistema de información poblacional) de la Agencia Valenciana de Salud, el total de niños de 6 años en el departamento es de 2.979 y el de 12 años de 2.903. Estas edades se seleccionan porque son las usadas por la OMS como referencia respecto a la valoración de la salud bucal en todo el mundo. Por otro lado, la edad de 12 años nos sirve, en última instancia, para observar la calidad del cepillado autónomo pues ya no aparece una dependencia tan grande de los padres en la higiene bucodental diaria.

El lugar donde se realizó el estudio fue la consulta de Odontopediatría de cada uno de los 8 centros de salud. Como técnica de selección se utilizó el muestreo consecutivo. La captación se consiguió a través de los niños que acudían a las UOP por primera vez o para su revisión perió- 
dica, durante el periodo comprendido entre noviembre de 2007 y abril de 2008 distribuyéndose en los grupos anteriormente mencionados según su edad. Para completar la muestra del grupo de 12 años se pidió a los pediatras que nos remitieran a los niños de esta edad que acudiesen a sus consultas y se divulgó el estudio en un diario local.

Recursos humanos: para la ejecución del estudio se cuenta con la participación de los 11 componentes de las 4 UOP del departamento. En la actualidad está formada por 4 odontopediatras y 7 higienistas dentales. Todos presentan una dedicación a tiempo completo, y el trabajo de campo se realizó dentro de la jornada laboral. Para asegurar la fiabilidad y validez de los resultados se realizaron 10 sesiones previas de 2 horas de duración dirigidas por el investigador principal, para exponer la sistemática de las exploraciones (se entregó documentación escrita a cada uno) y realizar un análisis de concordancia entre todos los participantes mediante un índice de Kappa en el diagnóstico de caries.

Tamaño de la muestra: para calcular el tamaño de la muestra se ha considerado un contraste unilateral, la media del índice $\mathrm{CAO}(\mathrm{S})$ (tabla I) a los 12 años es de 1,561 y la desviación típica de 0,125; el nivel de significación es de 0,05 y la po- tencia de 0,8 . Se considera el mismo tamaño tanto en el grupo en que se dan valores de las pruebas desfavorables como en el de los favorables. Tras el proceso estadístico con el programa informático Ene $2.0^{\oplus 11}$ obtenemos un valor de la muestra de 222 más un 10\% para incrementar el ajuste hacia una distribución normal, lo que hace un total de 244 niños de 12 años.

Para el tamaño de la muestra del grupo de los 6 años se sigue el valor del índice co(s) (tabla I), pues a esta edad prácticamente no vamos a encontrar dientes definitivos $y$, como referencia, es mejor el empleo de los valores sobre la dentición decidua. El valor co(s) a los 6 años es de 2,141, el intervalo de confianza al $95 \%$ es de 1,71-2,57 y siguiendo el mismo proceso estadístico anterior obtenemos un tamaño muestral de 286 reconocimientos.

Autorizaciones: antes de la ejecución de las pruebas se entregó a uno de los padres una hoja informativa sobre el trabajo de investigación, otra para el niño con un texto adecuado a su edad y una nota en la que se indicaban una serie de cuidados durante la hora previa a la cita: no comer ni beber nada, no masticar chicles, no lavarse los dientes y no utilizar colutorios. Por último, una declaración de consentimiento informado que nos 
entregaría firmada uno de los padres o tutores para poder incluir al niño en el estudio. Después se concertaba la cita del niño en la consulta de cada UOP.

Variables del estudio recogidas a través de la encuesta, la exploración bucal y las pruebas no invasivas:

1. Filiación: fecha de exploración, examinador, centro de salud, apellidos y nombre del niño, fecha de nacimiento, nacionalidad (extranjero es aquel niño de nacionalidad no española, hijo de padres extranjeros, que reside en nuestro país menos de 6 años), dirección, código postal, ciudad y teléfonos.

2. Anamnesis: nos interesa preguntar sobre las tres cuestiones primordiales en Odontología preventiva como son la frecuencia del cepillado diario, el consumo de azúcares entre comidas y el empleo de colutorios fluorados.

3. Índices de caries (tabla I): también para valorar mejor el riesgo del niño nos fijaremos en si hay caries en dientes de mayor resistencia a la misma como los incisivos o caninos, si se han afectado superficies con menor frecuencia de ser atacadas como las vestibulares o linguales-palatinas y si la evolución es de lesiones crónicas o activas (estas últimas son lesiones blandas de color amarillo o amarillo oscuro). La presencia de obturaciones en mal estado o la presencia de algu- na aparatología removible u ortodóncica serían variables a considerar para completar la parte descriptiva del estudio.

4. Pruebas complementarias:

- pH de la placa: usamos el producto GC Plaque Indicator Kit ${ }^{\oplus}$. Siguiendo las instrucciones recogemos la placa de los lugares interproximales del área molar (preferiblemente en la mandíbula) con un instrumento afilado y la introducimos en una solución indicadora durante un segundo. Posteriormente, la dejamos que fermente durante 5 minutos $y$ comprobamos el cambio de color según una tabla. Podremos obtener 4 posibles valores: $>7,6,5,60$ $<5,5$.

- Capacidad tampón de la saliva: empleamos el Saliva-Check Buffer ${ }^{\circledR}$ también de la casa GC. Se pide al niño que estimule la producción de saliva con la masticación de un trozo de parafina durante un minuto. Después debe echar la saliva en un recipiente. Con una pipeta se saca suficiente líquido y se vierte una gota en cada una de las tres almohadillas del test. Después de 2 minutos se calcula el resultado final valorando los cambios de color y comparándolos con una tabla. Los valores obtenidos nos darán la capacidad 
amortiguadora según: muy baja, baja o normal-alta.

- Índice de placa (índice de O’Leary): para su obtención se aplica con el dedo o un microcepillo el Plaque Disclosing gel ${ }^{\circledR}$ sobre las superficies dentales. Luego se hace circular la saliva producida entre los dientes durante un minuto, se enjuaga la boca con agua y se examinan las caras mesial, distal, vestibular y lingual de cada pieza dentaria. La placa quedará teñida de rosa, si se trata de placa reciente, o azul, si es placa de más de 48 horas. Posteriormente, se valora la presencia
(+) o no (-) de ambas tinciones en cada una de las 4 superficies dentales y se expresa porcentualmente la placa de un individuo de manera exacta. Se considera una buena técnica de cepillado cuando el valor del índice es inferior al $20 \%$ (figura 1).

- Las exploraciones se efectuaron con la luz de la lámpara de los sillones dentales de las consultas. En el diagnóstico se empleó una sonda de exploración y un espejo plano intraoral n. ${ }^{\circ}$. Las sesiones tuvieron una duración media para cada niño de unos 45 minutos.

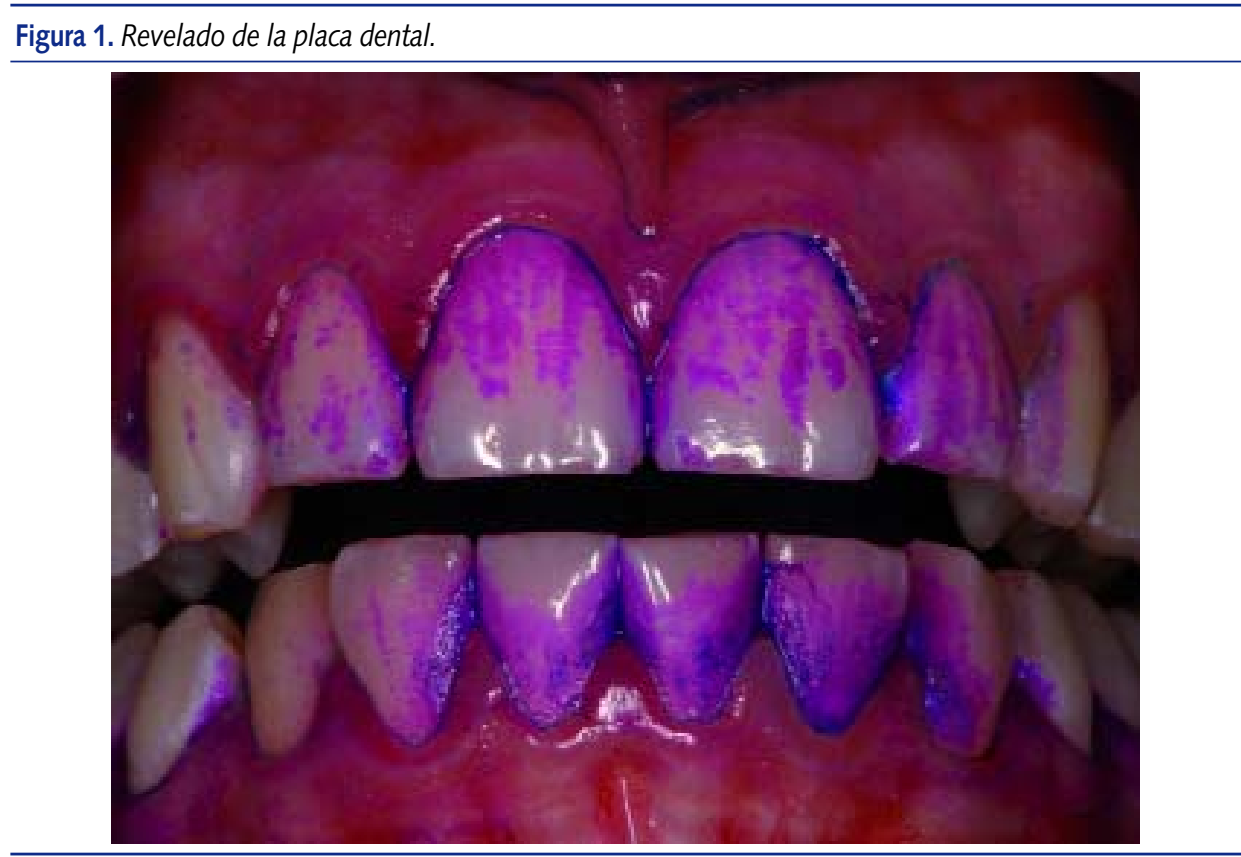


Análisis estadístico: para el análisis se emplea el programa estadístico SPSS 12.0 $0^{\circledR}$. La significación estadística se fija en $p<0,05$.

\section{Resultados}

Se realizaron un total de 597 exploraciones válidas (339 de 6 años y 258 de $12 ; 319$ varones y 278 hembras). Por centros la distribución se expresa en la tabla II.

La prevalencia de caries en el grupo de 6 años en dentición temporal es del $41,3 \%(140 / 339)$ y del $12 \%(31 / 258)$ a los 12 años mientras que la prevalencia de caries en dentición permanente es del $4,7 \%(16 / 339)$ a los 6 años y del 39,9\% $(103 / 258)$ a los 12 años. Se detallan los valores de los índices de caries para ambos grupos en la tabla III y los resultados descriptivos de la encuesta practicada a los padres que acudían con sus hijos en la tabla IV.

La distribución de los distintos valores encontrados en el pH de la placa, la capacidad tampón de la saliva y los niños con índice de placa (O’Leary) superior al $20 \%$ se reflejan en la tabla $\mathrm{V}$.

Otros resultados descriptivos de interés para la valoración del riesgo de caries son:

Tabla II. Distribución de reconocimientos por centro de salud

\begin{tabular}{lccc}
\hline Localidad* $^{*}$ & Frecuencia & Porcentaje & Porcentaje acumulado \\
\hline Altabix & 70 & 11,7 & 11,7 \\
Carrus & 62 & 10,4 & 22,1 \\
Crevillente & 68 & 11,4 & 33,5 \\
Pla & 80 & 13,4 & 46,9 \\
Raval & 93 & 15,6 & 62,5 \\
Santa Pola & 48 & 8,0 & 70,5 \\
Sapena & 95 & 15,9 & 86,4 \\
Toscar & 81 & 13,6 & 100,0 \\
Total & 597 & 100,0 & - \\
\hline${ }^{*}$ Municipios de Alicante. & & & \\
\hline
\end{tabular}

Tabla III. Valores de los índices de caries

\begin{tabular}{lcccc}
\hline Edad & co(d) & co(s) & CAO(D) & CAO(S) \\
\hline 6 años & 1,5 & 2,5 & 0,06 & 0,07 \\
12 años & 0,27 & 0,51 & 1,08 & 1,45 \\
\hline
\end{tabular}

Los valores en dentición temporal disminuyen con la edad por la exfoliación natural a diferencia de los de la dentición definitiva o permanente. La explicación de estos índices se describe en la tabla l. 
Tabla IV. Resultados de la encuesta practicada a los padres que acudían con sus hijos

\begin{tabular}{lrrr}
\hline & Frecuencia & Porcentaje & Porcentaje acumulado \\
\hline Cepillado dental diario & & & \\
Dos o más veces al día & 362 & 60,6 & 60,6 \\
Una vez al día & 171 & 28,6 & 89,3 \\
Ocasionalmente & 61 & 10,2 & 99,5 \\
No sabe/no contesta & 3 & 0,5 & 100,0 \\
Total & 597 & 100 & - \\
\hline Azúcares diarios & & & \\
Dos o más veces al día & 203 & 34,0 & 34,0 \\
Una vez al día & 163 & 27,3 & 61,3 \\
Ocasionalmente & 219 & 36,7 & 98,0 \\
No sabe/no contesta & 12 & 2,0 & 100,0 \\
Total & 597 & 100 & - \\
\hline Colutorios con flúor & & & 49,9 \\
Sí & 298 & 49,9 & 91,1 \\
No & 246 & 41,2 & 99,5 \\
Ocasionalmente & 50 & 8,4 & 100,0 \\
No sabe/no contesta & 3 & 0,5 & - \\
Total & 597 & 100 & \\
\hline Asistencia previa a la UOP & & & 85,8 \\
Sí & 512 & 85,8 & 99,7 \\
No & 83 & 13,9 & 100,0 \\
No sabe/no contesta & 2 & 0,3 & - \\
Total & 597 & 100 & \\
\hline
\end{tabular}

Tabla V. Resultados de las pruebas. Distribución de los distintos valores encontrados en el pH de la placa, la capacidad tampón de la saliva y los niños con índice de placa (O'Leary)

\begin{tabular}{lrrr}
\hline & Frecuencia & Porcentaje & Porcentaje acumulado \\
\hline pH de la placa & & & \\
$>7$ & 27 & 4,5 & 4,5 \\
6,5 & 226 & 37,9 & 42,4 \\
6 & 289 & 48,4 & 90,8 \\
$<5,5$ & 55 & 9,2 & 100,0 \\
Total & 597 & 100 & - \\
\hline Capacidad tampón de la saliva & & & \\
Muy baja & 203 & 34,0 & 34,0 \\
Baja & 163 & 27,3 & 61,3 \\
Normal/alta & 219 & 36,7 & 98,0 \\
Total & 597 & 100 & - \\
\hline Índice de placa (O'Leary) & & & 4,5 \\
$<20 \%$ & 27 & 4,5 & 100,0 \\
$>20 \%$ & 570 & 95,5 & - \\
Total & 597 & 100 & \\
\hline
\end{tabular}


- Un 5,2\% (31/597) de los niños son inmigrantes. Un estudio reciente realizado por el autor principal revela que la población inmigrante presenta unos índices de caries que casi triplican a los de los españoles ${ }^{12}$.

- Hay 38 niños (6,3\%) con lesiones en incisivos o caninos (se trata de piezas dentarias, en principio, resistentes a la caries).

- Hay 70 explorados $(11,7 \%)$ con al menos una caries en superficies vestibulares o palatinas/linguales (las superficies dentarias más sensibles a la caries son las oclusales y las interdentales).

- Existen caries con signos de actividad o de evolución aguda en 156 niños $(26,1 \%)$.

- Encontramos 14 niños (2,3\%) con obturaciones en mal estado o con caries recurrente.

- La aparatología ortodóncica favorece el desarrollo de la caries por su carácter retentivo de placa y está presente en 3 niños de 6 años y 22 de 12 , o sea, el 4,1\% (25/597).

- Tan solo en el 6,2\% (21/339) de los niños de 6 años y en el 2,3\% $(6 / 258)$ de los de 12 encontramos unos valores inferiores al $20 \%$ de placa. En el 56,3\% (336/597) de los reconocimientos detectamos placa coloreada azul o de más de 48 horas sin remover de la boca.

Por último, detallamos los resultados relacionados con los 3 últimos objetivos específicos de este estudio:

- Existe una relación significativa $(\mathrm{p}<$ $0,05)$ entre los resultados del $\mathrm{pH}$ de la placa transformando los valores iniciales 6,5 y $>7$ en alcalino y los valores 6 y $<5,5$ en ácido ( $\mathrm{pH}$ placa) con el índice co(s) en el grupo de 6 años. En el grupo de 12 años también hay significación estadística entre los valores alcalino y ácido con el índice $\mathrm{CAO}(\mathrm{D})$.

- No encontramos relación estadística entre la capacidad tampón de la saliva y los valores del co(s) en los niños de 6 años, ni con los valores del $C A O(D)$ en el grupo de 12 años.

- No obtenemos asociación estadística entre los valores de los índices co(s) y $C A O(D)$ a los 6 y 12 años respectivamente con las medias de los índices de placa coloreada.

\section{Discusión}

El principal objetivo de las exploraciones bucales en Atención Primaria es la detección de problemas lo más precozmente posible y la valoración del riesgo de caries. Solo así se utilizarán los recur- 
sos disponibles con la mayor eficiencia posible.

La caries es una enfermedad infectocontagiosa crónica y multifactorial influenciada por el medio oral, la genética y el comportamiento higiénico-dietético del sujeto. No existe ningún modelo que usando factores de riesgo pueda predecir con exactitud el desarrollo de la enfermedad. El explorador con experiencia debe intuir y conocer la fuerza que cada factor de riesgo tiene en un determinado niño. Todo profesional debe experimentar de forma prospectiva los distintos factores $y$ ponerles la potencia que considere oportuno. Se convierte en imprescindible la creación de puestas en común donde se debatan estos temas.

No hemos tenido problemas a la hora de completar el tamaño de la muestra respecto a los niños de 6 años, pero con los de 12 hemos recurrido a las consultas de Pediatría para facilitar su derivación. Ya sabemos que los padres nos traen a sus hijos especialmente alrededor de los 6 años (al inicio de la dentición mixta) pero su asistencia sufre un descenso continuado hasta los $15^{12}$. La distribución de la muestra entre los centros de salud ha sido muy homogénea.

Los valores de los índices de caries son similares a los encontrados en el Estudio de salud bucodental infantil en la Co- munidad Valenciana de 2004'. Es un dato más a favor de la representatividad de la muestra estudiada.

Ante las preguntas puntuales sobre la frecuencia del cepillado, el consumo de azúcares, el empleo de colutorios fluorados o la asistencia previa a una UOP, les damos un valor instructivo-motivador y de la mayor o menor valoración que tiene la salud bucodental en el seno familiar. Realmente tienen poca fuerza predictiva $y$, aunque omitimos los resultados por ser muy prolijos, no hemos encontrado significación estadística al cruzarlas con los índices de caries. No cabe duda de que deberíamos objetivar o cuantificar la calidad del cepillado, la escala de peligrosidad de los azúcares o hábitos alimenticios, el uso idóneo y continuado de los colutorios fluorados y las revisiones periódicas. Solo así y en el ámbito familiar se podrían realizar estudios longitudinales en los que, a buen seguro, obtendríamos resultados acordes a lo que la evidencia clínica nos dice.

La obtención del pH de la placa ha sido la única prueba de este fabricante que ha presentado una relación positiva entre la placa ácida con niveles más elevados de caries. El producto debe mejorarse técnicamente: en ocasiones hemos encontrado alguna dificultad para recoger suficiente placa que pudiese visualizar bien 
los cambios cromáticos graduales relacionados con los distintos valores $y$, por ello, se desestimaron en el estudio. El pH de la placa se acidificaría con un elevado consumo de azúcares (también lo corrobora el fabricante) pero la relación entre ambas variables no ha dado una significación estadística positiva. Tal vez sirva a la hora de confirmar un descenso o aumento en el consumo de dulces a lo largo del tiempo con la repetición del test al mismo paciente. De esta forma se abre la puerta a nuevos estudios con este objetivo.

El test de la capacidad tampón de la saliva no presentó unos virajes de color tan nítidos como los que vienen en el manual de instrucciones. Esta cuestión introduce un sesgo de interpretación por parte del observador. Por otro lado, se debería usar en otros grupos poblacionales con edades diferentes y en condiciones fisiopatológicas distintas para obtener otras conclusiones, ya que la capacidad tampón viene determinada por el conjunto de las sales disueltas en la saliva y esta varía mucho con la edad, estados anímicos, fármacos, etc. En definitiva, aunque para nosotros no ha resultado interesante en los niños, podría serlo en otros grupos.

El gel identificador de la placa sí ha resultado ser un producto muy adecuado pero sin valor predictivo en un momento puntual. Es fácil su identificación en la bo- ca del paciente y nos ha gustado el cambio a azul si se trata de placa madura. El recuento no conlleva problema alguno cuando ya se tiene cierta práctica y sirve mucho para valorar la mejora de la calidad del cepillado en las visitas sucesivas a la consulta. Es muy llamativo el bajísimo porcentaje de niños con una técnica de cepillado correcta, siendo aún más bajo en los de 12 años donde la tutela de los padres es menor en este aspecto. Resulta también interesante que, mientras el $56,3 \%$ de los niños presenta placa de más de 48 horas de evolución, según los datos de la encuesta, el $89,2 \%$ de los niños se cepillan al menos una vez al día. Esto nos plantea de nuevo que la validez de la encuesta no va más allá de un valor instructivo o motivador, y verificar también el desconocimiento de los padres respecto a la calidad del cepillado de sus hijos. Y es aquí donde todos los profesionales de Primaria debemos pasar de la simple recomendación a crear unos protocolos que controlen la mejora de la técnica.

\section{Conclusiones}

1. La prevalencia de caries y los índices de caries son similares a los encontrados en nuestro entorno.

2. Los valores de la frecuencia del cepillado mejoran a los ideales respecto a los hábitos alimenticios saludables, es decir, 
es más fácil cepillarse los dientes que controlar la ingesta de azúcares entre comidas.

3. El elevado porcentaje de niños que han realizado asistencias previas a las UOP nos indica la valoración muy positiva por parte de los padres a la hora de llevar a sus hijos a las revisiones periódicas bucales.

4. Los valores intermedios del $\mathrm{pH}$ de la placa son los que presentan la mayoría de las pruebas realizadas.

5. Los valores normales-altos de la capacidad tampón de la saliva tan solo representan algo más de un tercio de los niños explorados.

6. Resulta muy difícil encontrar niños cuyo cepillado sea correcto. Debemos implicar más a los padres en el grupo de los 6 años y nosotros, los profesionales, actuar más en las consultas con los de 12.

7. A aquellos niños con lesiones en dientes o superficies resistentes, con aparatología ortodóncica, con caries recidivantes en piezas obturadas $y$, sobre todo, en presencia de caries activas (se encuentran en el $26,1 \%$ ) se les debe considerar como pacientes de riesgo y a los que debemos aplicar todo o parte de nuestro arsenal preventivo.

8. Solo la prueba del pH de la placa resultó positiva a la hora de compararla con los índices de caries. Sin embargo, el
pH de la placa ácida no se relaciona de forma significativa con una respuesta por parte de los padres de que la frecuencia en el consumo de azúcares es elevada.

9. Se hace imprescindible por parte de los laboratorios que sigan buscando tests que resulten sencillos, económicos, fácilmente cuantificables y tengan utilidad no solo en el aspecto motivador de los pacientes sino también en el predictivo. Los profesionales clínicos, con nuestros estudios especialmente prospectivos, debemos validarlos para su uso en Atención Primaria.

10. En este trabajo se han evaluado la mayoría de los factores que se consideran como de riesgo de caries, a excepción del recuento de colonias mediante cultivo del Streptococcus mutans. Queda para un futuro próximo la investigación a la hora de determinar la mayor o menor potencia predictiva de estos u otros factores. De momento la historia pasada de la enfermedad sigue siendo el valor más relevante, como así lo corroboran la mayoría de estudios.

\section{Agradecimientos \\ Rosa Guaita Sancho (higienista den- tal), María Belén Alcaraz Illán (higienista dental), María Teresa Berenguer Mira (higienista dental), Ana Martínez Valero (higienista dental), Fini Carrillo García}


(higienista dental), Amada Llorente López (higienista dental), Esther Miguel Pardo (higienista dental), Blanca Lumbreras Lacarra (epidemióloga), María Asunción Pastor Climent, Federico Villagrasa Rocher (epidemiólogo).

\section{Financiación}

Fundación para la Investigación Biomédica del Hospital General Universitario de Elche. N. ${ }^{\circ}$ de proyecto $27 / 2007$. Cantidad asignada: 5.353,00 euros.

\section{Bibliografía}

1. Almerich Silla JM, Montiel Company JM, Zurriaga Llorens $O$, Montoso Sullana $A$, Redondo Gallego MJ. Estudio de salud bucodental en la Comunidad Valenciana 2004. Valencia: Generalitat Valenciana; 2005.

2. Rioboo García R. Epidemilogía de la caries dental. En: Odontología preventiva y Odontología comunitaria. Tomo II. Madrid: Ediciones Avances Médico-Dentales S.L.; 2002. p. 951-93.

3. Cuenca Sala E, Baca García P. Caries: fundamentos actuales de su prevención y control. En: Odontología preventiva y comunitaria. Barcelona: Masson, S.A.; 2005. p. 19-40.

4. Tagliaferro EP, Pereira AC, Meneghim MC, Ambrosano GM. Assessment of dental caries predictors in a seven year longitudinal study. J Public Health Dent. 2006;66:169-73.

5. Zhang Q, Bian Z, Fan M, van Palenstein Helderman WH. Salivary mutans streptococci counts as indicators in caries risk assessment in 6-7-yearold Chinese children. J Dent. 2007;35:177-80.

6. David J, Raadal M, Wang NJ, Strand GV. Caries increment and prediction from 12 to 18 years of age: a follow-up study. Eur Arch Paediatr Dent. 2006;7:31-7.
7. Ruiz Miravet A, Montiel Company JM, Almerich Silla JM. Evaluation of caries risk in a young adult. Med Oral Patol Oral Cir Bucal. 2007;12: 412-8.

8. Barbería Leache E, Boj Quesada JR, Catalá Pizarro M, García Ballesta C, Mendoza Mendoza A. Pruebas complementarias y plan de tratamiento. En: Odontopediatría. Barcelona: Masson S.A.; 1995. p. 35-51.

9. Sakuma S, Nakumara M, Miyazaki H. Predictors of dental development in 1,5 year-old highrisk children in the Japanese public health service. J Public Health Dent. 2007;67:14-9.

10. Pearce IE, Dong YM, Yue L, Gao XJ, Purdie $G L$, Wang JD. Plaque minerals in the prediction of caries activity. Community Dent Oral Epidemiol. 2002;30:61-9.

11. Badiella Busquets $L$, Pedromingo Marino A. Cálculo del tamaño muestral con el programa Ene 2.0. Madrid: GlaxoSmithKline S.A.; 2005 [consultado el 11/01/2009]. Disponible en www.e-bio metria.com/ene-ctm/files/ManualENE30.pdf

12. Blasco Sánsano R, Pastor Climent MA, García Espinosa S, Blasco Berná L. Defectos del desarrollo del esmalte dentario en los primeros molares definitivos. Rev Pediatr Aten Primaria. 2007;9: 205-17. 